\title{
An Exploratory Study of Altruism in Greek Children: Relations with Empathy, Resilience and Classroom Climate
}

\author{
Sophie Leontopoulou \\ Department of Primary Education, University of Ioannina, Ioannina, Greece. \\ Email: sleon@cc.uoi.gr \\ Received September 19 $9^{\text {th }}, 2010$; revised September 24 $4^{\text {th }}, 2010$; accepted September $27^{\text {th }}, 2010$.
}

\begin{abstract}
The aims of this exploratory study were two-fold: a. to identify any relations between children's altruism and a set of demographic and other personal and social characteristics of Greek children, such as empathy, resilience and classroom climate; and $b$. to examine the psychometric properties of a newly-developed measure of altruistic behavior in children, namely the Altruistic Behavior Questionnaire (ABQ). 232 male and female students of the $5^{\text {th }}$ and $6^{\text {th }}$ class of Primary School in Northern Greece participated in this study. The ABQ was found to have adequate internal consistency and concurrent and construct validity. Using a hierarchical regression analysis, altruism in children was found to be reliably predicted by participants' gender and academic performance, by empathy and also by resilience; nevertheless, the more socially determined variable of classroom climate only marginally predicted altruism. The importance of including training in the development and manifestation of altruism in emotional education programmes and resilience interventions at school is highlighted.
\end{abstract}

Keywords: Altruism, Empathy, Resilience, Classroom Climate, Children, Gender Differences

\section{Introduction}

The present study ${ }^{1}$ deals with an important, albeit little investigated topic, that of the measurement, development and study of altruism in children. The aim of this exploratory study is two-fold. Primarily, it seeks to map the largely uncharted area of altruistic behavior in Greek pre-adolescent children, from the standpoint of the emergent positive psychology. Secondly, it tries to address the increased emphasis on the need for low-cost, well-tested measures related to children's development, by way of constructing a new scale of altruism for children. In the following sections a review of altruism and prosocial behavior in children will set the scene for the examination of other constructs, both individual and social in nature, which could be argued to be related to altruism, such as empathy and resilience, but also classroom climate.

\section{Altruism and Prosocial BEHAVIOR in Children}

The term "prosocial behavior", coined by Wispé (1972) in contrast to "antisocial behavior", covers a range of actions with positive connotations, such as altruism, helping behavior and cooperation. Piliavin and her colleagues (1981) described prosocial behavior as a broad category of actions "defined by society as generally beneficial to other people and to the ongoing political system" (p. 4). The philosopher August Comte was the first to coin the term "altruism" as a contrast to "egoism" ([1851] 1975). In recent times, altruism has been treated largely as a category of prosocial behavior, signifying either a particular type of helping "carried out to benefit another without

$\overline{{ }^{1} \text { Parts of this paper (such as data collection and initial description of the }}$ ABQ) are based on the undergraduate thesis of An. Magaki, S. Serifis and V. Goula, completed under my supervision. anticipation of rewards from external sources" (Macaulay \& Berkowitz, 1970); or a type of motivation, be it egoistic or altruistic in nature (Batson, 1991). Eisenberg and Mussen (1997) used the two terms interchangeably, while making a distinction between the two. For them, prosocial behavior is defined as actions intended to help or benefit other people or groups of people, independent of one's motives; altruism, on the other hand, refers to actions intended to help others, but which are characterized by purely internal motives, such as sympathy and self-esteem, as opposed to external motives, such as personal gain and reciprocation. Warneken and Tomasello (2009) proposed a typology of prosocial behavior, comprising four elements: comforting (i.e., providing emotional support to others), sharing (i.e., giving food or objects to others), informing (i.e., providing useful information for others) and instrumental helping (i.e., acting on behalf of others' goals). Kakavoulis (1998) proposed a similar four-fold typology of altruism, i.e., sharing, helping, cooperating and comforting, upon which the development of the Altruistic Behavior Questionnaire $(A B Q)$, a scale constructed specifically for the needs of this study, was based (see pp. 380).

In recent years there has been some discussion as to the roots of human altruism. Warneken and Tomasello (2009) claimed that altruistic tendencies "reflect a natural predisposition. Socialization can build upon this predisposition, but it is not its primary source. Human cultures cultivate rather than implant altruism in the human psyche" (p. 465). This natural predisposition does not necessarily contradict the Darwinian concept of natural selection; rather, it refines it by suggesting that mechanisms such as kin selection, reciprocal altruism and group selection facilitate the emergence of acts of altruism (Piliavin, 2009). Furthermore, human beings are pluralistically motivated, meaning that they can be motivated by altruism, by self-interest, or by a combination of the two (Sober \& Wilson, 1998). 
Hay (2009) reported that toddlers often exhibit helping and sharing behaviors toward others at higher rates than aggressive behavior. He suggested that, while prosocial behavior occurs early in life and is underpinned by biological factors, it should nevertheless be examined taking into consideration the individual characteristics of infants and of the situational context within which the episodes of prosocial behavior take place. He argued that "selective pressures in human evolution have favoured sociability, which could lead to aggression or altruism, depending on context and the nature of the rearing environment. Any social behavior shown in infancy may have multiple functions, at phylogenetic, ontogenetic and episodic levels of analysis" (p. 473).

Research carried out with older children has revealed that prosocial behavior is affected by a number of factors, such as their altruistic predisposition, which, according to Eisenberg (1992) allows children to be happier, express their emotions more freely, be more sociable, enjoy higher self-esteem and be better adjusted to their environment; also, their emotional state, cognitive development, empathy and sympathy, and understanding of the reasons for someone's misery. In any event, age seems to differentiate the manifestation of altruism in children, in terms of both number and complexity of altruistic acts (Radke-Yarrow, Zahn-Waxler, \& Chapman, 1983). Helping behavior tends to augment around age eight for children, only to drop later and rise again during childhood. Midlarsky and Hannah (1985) interviewed children and adolescents and found that younger children often hold back from offering help, only because they feel awkward or unable to help. On the other hand, when pre-adolescents and adolescents refrain from offering help, they do so out of fear that their offer will be rejected, or that the person at the receiving end will feel awkward.

Research has also shown that altruism is mostly manifested toward individuals of the same gender, ethnicity and idiosyncrasy (Kakavoulis, 1997). However, there is mixed evidence as to the effects of gender, socio-economic status and family size on altruism. Radke-Yarrow and her colleagues (1983) have shown that girls tend to exhibit altruistic behavior slightly more often than boys, but not significantly so. Differing socialization processes and social expectations regarding the characteristics, behaviors and roles of women and men can go some way toward explaining such differences, if indeed they exist (Kakavoulis, 1999). As far as the relation of socio-economic status with altruism is concerned, research has either failed to identify any significant differences or has generated mixed results. This conflicting evidence can be attributed to either the different childrearing practices followed by parents from different socio-economic backgrounds, or to the research design and methods used to study the phenomena at hand (Kakavoulis, 1999). Research is also inconclusive as to the influence of family size on altruism. Some researchers report that children raised in families with many children tended to be more generous and share their belongings without expecting something in return. Other researchers, however, maintain that a smaller number of siblings were positively related to helping behavior in an emergency. They attributed this finding to these children enjoying higher levels of self-esteem and taking the initiative more readily (Staub, 1971). One of the aims of the present study was to explore the effects of demographic factors on altruism.

\section{Altruism and Empathy}

There seems to be widespread agreement that the mediating, intervening process that allows people to help others altruistically, i.e. without expecting rewards or avoiding punishment, is empathy (Batson, 1991; Hoffman, 1981). Hoffman (2000) defined empathy as "an affective response more appropriate to another's situation than one's own" (p. 4). Empathy comprises not only emotional aspects but also cognitive elements, such as perspective taking and causal attribution. Hoffman maintained that empathy and concern for others are what make social life possible, even though he recognized the inevitable conflict between self-interest and social obligations (Eisenberg, \& Morris, 2001). According to Piliavin (2009), "the brain is wired for empathy and other-oriented action and the hormone system contributes to this disposition" (p. 215). Moreover, altruism and empathy can be trained in both children and adults, since one can develop new role identities throughout life, "some of which can be altruistic in nature, through a process of identity development aided by the expectations held by others" (p. 216).

Stalikas and Hamodraka (2004) recognized that children who perceive someone's pain or sadness may display empathy and may take steps to comfort them. In this respect empathy is considered the precursor of moral development. Research has shown that children who display greater empathy toward others are less aggressive, are more prone to help others and develop a more positive type of moral judgment. Empathy develops in stages during infancy and childhood and its manifestations are largely affected by the quality of the relationship between the child and the person in difficulty, as well as by one's motivation to help, as suggested by Hoffman (2000). Hoffman argued that empathy is an important motivator of prosocial behavior in children and adults alike. Nevertheless, research has revealed differentiated empathic responses between the two: unlike adults, children who tend to experience more negative emotions also exhibit lower levels of empathy and sympathy, possibly due to their tendency to experience negative emotions intensely (Eisenberg \& Morris, 2001). In addition, children who are more able to regulate their attention and behavior also tend to be more empathic. Eisenberg and Morris (2001) reported that, among elementary school children, regulation interacts with their dispositional emotionality to predict empathy, thus facilitating the selection of those children who would benefit more from specific interventions at school teaching emotion regulation strategies. The authors also suggested that, according to Hoffman, genetic factors contribute to individual differences in proneness to experience empathy; however, environmental factors, especially socialization processes, also contribute to individual differences in children's empathy and distress, such as discipline and general parenting style, as well as parental emotion-related practices. One of the aims of the present study was to explore the interconnections between altruism and resilience in children.

\section{Altruism and Resilience}

To the best of our knowledge, the relationship between altruism and resilience, defined as good adaptation despite risk and adversity, has not been studied as yet. Kakavoulis (1999) reviewed research evidence that unearthed links between children's altruistic behavior and their social and emotional adaptation, as indexed by the construct of ego resilience, a construct 
different to those of resilience (defined as the ability to modify one's level of ego control, or the degree and kind of control one exerts over one's impulses; see Block 1993), self-regulation and popularity. Long and Lerner (1974) reported results from a longitudinal study which showed that children who tended to help, cooperated well with others, were interested in moral issues and were kind to other children also scored highly on indices of ego resiliency and self-regulation of their behavior (i.e., ability to postpone immediate satisfaction). McGuire and Weisz (1982) reported findings which showed that children who helped others, were more interested in others and contributed generously to fundraising, were rated by their teachers as being more able to interact with other children, were more popular and made close friends. This study aimed to examine children's altruistic behavior in relation to their levels of resilience.

\section{Altruism and Classroom Climate}

Social learning theory holds that prosocial behavior in children is built on the basis of the moral standards available in their environment. Children tend to imitate the behavior of role models in their world, especially parents, siblings and schoolteachers. Research has shown that the more children observe someone engaging in prosocial behaviors, the more they tend to share their belongings and help others (Radke - Yarrow, \& Zahn - Waxier, 1986). As the school is irrefutably a context of vital importance for the socialization of children, it can play a key role in building, exercising and maintaining a range of prosocial behaviors in children too. The school climate is the frame that allows for the development of healthy prosocial interactions between children and adults involved in the educational process. The terms classroom climate and educational atmosphere (coined by Bollnow, 1970) are used interchangeably to indicate the special conditions that need to exist in the classroom and in the school in order for education and learning to take place. The terms include those interpersonal relations between teachers and students that have emotional connotations, as well as the relations between students, which affect their learning and behavior alike and can shape the development of their personality (http://1 grpe.pel.sch.gr/modules.php?op=modload\&name $=$ News\&file $=$ article \&sid $=1247)$.

According to Rutter (2000), a number of studies with national and international samples, both cross-sectional and longitudinal in nature, showed that the classroom climate seriously affects students' well-being, academic performance and employment rates. Altruism is often reported in research to counteract aggression, bullying and victimization. For instance, Sutton and Keogh's (2000) results suggested that a competitive classroom climate may lead to higher levels of aggression. On the other hand, positive peer relations and networks were proven to provide support to withstand emotional difficulties and cope with them effectively, to help students sustain their academic efforts and to give comfort to others in need (StantonSalazar \& Spina, 2005). School-based programs for the development of prosocial behavior in children are often based on encouraging cooperation among students. Cooperative learning at school is known to affect students' perceptions of support, help and friendship and acceptance of diversity (Johnson, \& Johnson, 1983). One of the main aims of this study was to explore how different dimensions of the classroom climate affect children's altruism.

\section{Aims of the Study and Research Hypotheses}

This largely exploratory study suggests that the investigation of altruism needs to be set within the general framework of positive psychology, so that it can be examined under a new conceptual light. The discipline of positive psychology, as defined by its founder Seligman, is "the scientific study of positive experiences and positive individual traits, and the institutions that facilitate their development" (http://americanhumanist.org/hnn/archives/index.php?id=298\&article=1). It includes the study of positive emotions, positive character traits, and positive institutions (http://www.authentichappiness.sas.upenn. edu/Default.aspx\#). Positive emotions can help people be contented with the past, happy in the present and hopeful for the future. Positive character traits, defined by Seligman as strengths and virtues, such as resilience, creativity and integrity, can aid both younger and older individuals to overcome stress and difficulty. Positive institutions can foster better communities that are characterized by justice, responsibility and a sense of meaning in society at large (Piliavin, 2009). Altruism, when seen in this light, can be linked to favourable mental and physical health outcomes in adversity. Any attempt to shed some light on the factors and mechanisms involved in the development and manifestation of altruism, either individual or social in nature, such as empathy, self-esteem, resilience or classroom climate, can provide useful guidelines for the development of training programs and successful interventions at home, at school and in the community.

There is very little empirical support of the ways that altruism relates to and is affected by a set of positive personal and social characteristics in Greek children. Different types of altruistic acts that fall into the four broad categories of prosocial behavior presented above, i.e., sharing, helping, cooperating and comforting, need to be examined for their interconnections with positive aspects of human development within a Greek socio-cultural framework. Based on the above, the aims of the present study were shaped as follows. Firstly, the study aimed to examine any effects of demographic variables, such as age, gender, socio-economic status and family size, as well as academic performance, on children's altruism. Secondly, its object was to investigate whether altruism is connected to and influenced by: a. personal characteristics of children, such as empathy, but also resilience, a concept which includes the study of the effects of adversity on adaptation, thus opening new directions in the study of altruism and prosocial behavior; and $b$. characteristics of children's social environment, such as the school climate. Thirdly, the present study had a methodological focus, which consisted in developing and measuring the psychometric properties of a new scale of altruistic behavior, the Altruistic Behavior Questionnaire (ABQ; see p. 8 below for details) in a sample of Greek children on the threshold of adolescence. This questionnaire was constructed in response to the absence of a measure of prosocial behavior developed for and based on the particular altruistic behaviors and acts demonstrated by Greek children.

\section{Method}

\section{Sample}

Two hundred and thirty two males $(52.6 \%)$ and females 
$(47.4 \%)$ in the $5^{\text {th }}(47.8 \%)$ and $6^{\text {th }}(52.2 \%)$ class of Primary Schools at the city of Ioannina in Northwestern Greece participated in this study. Most students came from average socioeconomic status homes $(62.1 \%$ ), while $23.7 \%$ came from higher and $14.2 \%$ from lower socio-economic status homes. $91.8 \%$ had at least one other sibling, and $8.2 \%$ were only children. $93.1 \%$ of the sample consisted of Greek students born and raised in Greece, 3.4\% of Greek students raised abroad, and 3\% were European students. Most students' grades in the courses of Greek Language and Mathematics, the courses considered central to the Greek education system, were good: $55.4 \%$ in Language and $50.9 \%$ in Mathematics received top grades (10/10); $32.8 \%$ and $33.2 \%$ received very good grades $(9 / 10)$; and $11.6 \%$ and $15.9 \%$ received good grades $(8 / 10)$, revealing patterns typically found in Greek schools.

\section{Procedures}

After initial contacts with the school principals and course teachers, permission was granted to administer the questionnaire battery to students during school hours to fill in. Once parental permission was obtained, students were briefed prior to answering the questionnaire as to the main aim of the study and what would be required of them, and were also reassured regarding anonymity. Completion time was about one academic hour, during which researchers and the course teachers were present and available for clarifications.

\section{Measures}

Demographic information on participants was gathered using a number of questions on students' class at school, gender, socioeconomic status, origin and grades in the lessons of Greek Language and Mathematics, which are considered the two main lessons in Greek Primary Schools.

The Altruistic Behavior Questionnaire (ABQ; Erotimatologio Altrouistikis Symperiforas, EAS) was constructed to measure children's altruistic behavior (see Appendix 1). Twenty questions were developed based on the work of Kakavoulis (1999) and the four dimensions of altruism he identified as key concepts, i.e. sharing, helping, cooperating and comforting. Based on his categorization of acts of altruism, five actions falling into each category were selected from a longer list of altruistic actions that Greek parents reported they had observed their children perform (as described in Kakavoulis, 1999, p. 138) and subsequently turned into questions, which were used in the final questionnaire. For instance, the action "He/she intervenes in order to settle a dispute" was rephrased as "Do you help two classmates of yours to reconcile when you see them having an argument?"; the action "He/she keeps a place to offer it to someone" was rephrased as "Do you offer your seat to someone older at a school function?" The questions were rated on a four-point Likert-type scale (i.e., almost never, sometimes, most of the time, always). All questions were positively phrased, so that a higher score on the scale indicated higher altruistic behavior. Cronbach's $\alpha$ for the whole scale was satisfying, $\alpha=.78$ (the values for each item ranged from $\alpha=.75$ to $\alpha$ $=.80$ ). A pilot test was conducted prior to including the final questionnaire to this study's questionnaire battery for completion at school. No changes were made to the scale, however, as children were presented with no difficulties as far as phrasing and comprehension were concerned.
An Index of Empathy for Children and Adolescents (Bryant, 1982). Based on A Measure of Emotional Empathy, Mehrabian \& Epstein, 1972. Greek translation by Tsitsas) was used to index empathy in our study. The scale consists of 22 items, answered by "yes" or "no". A high score indicates higher empathy. Sample items include "It makes me sad to see a girl who can't find anyone to play with" and "It's hard for me to see why someone else gets upset". Cronbach's $\alpha$ for our sample was $\alpha=0.52$.

Wagnild and Young's (1993) Resilience Scale, as modified by Neill and Dias (2001; Greek translation by Leontopoulou) was used to measure resilience. This 15-item Likert-type scale is scored on a 7-point agree-disagree scale $(1=$ agree, $7=$ disagree). All questions are positively phrased so that a high score on the scale suggests higher resilience. Sample questions include "When I make plans I follow through with them" and "I keep interested in things". The initial authors report that the scale has concurrent validity with regards other scales of morale, life satisfaction and depression, while Neill and Dias (2001) report Cronbach's $\alpha=.91$. Reliability in the Greek sample was $\alpha=0.73$.

My Class Inventory (MCI; Fraser, Anderson and Walberg, 1982. Greek translation and adaptation by Matsagouras, 2000) scale was used to index students' perceived classroom climate. The scale consists of 25 items which are answered by either "yes" or "no". MCI assesses five elements which are indicative of the whole psychological climate in the classroom at Primary School. It comprises the following subscales: a. satisfaction (for our sample Cronbach's $\alpha$ was $\alpha=.66$ ); b. friction $(\alpha=.69)$; c. competitiveness $(\alpha=.51)$; d. difficulty $(\alpha=.72)$; and e. cohesiveness $(\alpha=.67)$.

\section{Results}

Means, standard deviations and correlations among the study variables are shown in Table 1, p. 381. Altruism was significantly and positively correlated with empathy and resilience ( $\mathrm{r}$ $=.35, \mathrm{p}<.001$; and $\mathrm{r}=.46, \mathrm{p}<.001$, respectively). Empathy was also positively correlated with resilience $(r=.17, p<.01)$ and with the satisfaction subscale of the classroom climate variable $(\mathrm{r}=.24, \mathrm{p}<.01)$, suggesting that empathy is related to a satisfying classroom climate. Reversely, empathy was negatively related with both subscales of the classroom climate which have negative connotations, namely friction $(\mathrm{r}=-.14, \mathrm{p}$ $<.05)$ and competitiveness $(\mathrm{r}=-.16, \mathrm{p}<.05)$. A similar picture emerged for resilience, which was positively correlated with the positive aspects of the classroom climate, i.e., satisfaction ( $\mathrm{r}$ $=.16, \mathrm{p}<.05)$ and cohesiveness $(\mathrm{r}=.13, \mathrm{p}<.05)$, and was negatively correlated with the negative aspect of friction $(\mathrm{r}=$ $-.15 \mathrm{p}<.05)$.

Since moderate, but significant positive correlations were found between altruism, empathy and resilience, further analyses were carried out to determine whether these measures are conceptually distinct from each other, as well as whether they are aspects of a higher order concept. A hierarchical regression analysis of resilience on the two more closely related concepts of empathy and altruism was performed, which also included demographic variables at the first step, such as gender, class, socio-economic status, siblings, origin and academic performance (Table 2, p. 381). While the influence of the latter was not significant, both empathy and altruism were found to be 
significant predictors of resilience. In particular, altruism was found to contribute unique variance at the last step of the regression equation, even after the effects of empathy were accounted for, thus suggesting that altruism is distinct to empathy.

Furthermore, a factor analysis was performed on all three positive psychology measures of altruism, empathy and resilience, to examine any possible communality they might share. Indeed, a single factor emerged from the factor analytical procedure (principal components analysis, varimax rotation), which accounted for $55.96 \%$ of the total variance. This finding suggested that, while altruism, empathy and resilience are distinct, according to the results of the hierarchical regression performed above, they also all load on a higher order concept, which can be termed positivity. Taken together, the above results offer some support to $\mathrm{ABQ}$ having adequate construct validity.

\section{Demographic Differences}

A series of one-way ANOVAs were calculated to explore any differences among the demographic characteristics of participants and the other study variables. In terms of altruism, females were found to be more altruistic that males $(\mathrm{F}(1,230)=8.46, \mathrm{p}$ $<.01)$. Origin also seemed to differentiate students' altruistic behavior, since youths from European countries scored higher on altruism than all others $(\mathrm{F}(3,228)=2.69, \mathrm{p}<.05)$.

Females exhibited more empathy than males $(\mathrm{F}(1,230)=$ $20.63, \mathrm{p}<.001)$. With respect to resilience, students who excelled in the Greek Language course were found to be more resilient that students who had good and average grades in this course $(\mathrm{F}(3,228)=2.94, \mathrm{p}<.05)$.

As far as classroom climate was concerned, younger students were found to perceive it as more difficult than older students $(\mathrm{F}(1,230)=5.27, \mathrm{p}<.05)$. Students from average and lower socio-economic status homes perceived more competitiveness in their classroom climate than students from higher socio-economic status homes $(\mathrm{F}(2,229)=3.31, \mathrm{p}<.05)$. In addition, children with no siblings appeared to be more satisfied by their classroom climate than children who had other siblings ( $F$ $(1,230)=4.70, p<.05)$. Students who excelled in both Greek Language and Mathematics were more satisfied with their classroom climate $(\mathrm{F}(3,228)=2.82, \mathrm{p}<.05$; and $(\mathrm{F}(3,228)=$ $3.59, \mathrm{p}<.01$, respectively); these students, compared to others, also thought that the classroom climate was not difficult (for Greek Language, $\mathrm{F}(5,224)=6.62, \mathrm{p}<.001$; for mathematics, $\mathrm{F}(3,228)=3.28, \mathrm{p}<.05)$. Students who excelled at Mathematics perceived their classroom climate as more cohesive ( $F$ $(3,228)=5.88, \mathrm{p}<.001)$; reversely, students with poor grades in Mathematics experienced more friction in their classroom climate $(\mathrm{F}(3,228)=4.49, \mathrm{p}<.01)$.

Table 1.

Means, standard deviations and correlations among altruism, empathy, resilience and the classroom climate subscales (i. e. satisfaction, friction, competitiveness, difficulty and cohesiveness).

\begin{tabular}{|c|c|c|c|c|c|c|c|c|c|}
\hline & Mean & S. D. & Altruism & Empathy & Resilience & Satisfaction & Friction & Competitiveness & Difficulty \\
\hline Altruism & 2.98 & 0.40 & - & & & & & & \\
\hline Empathy & 1.35 & 0.14 & $.35 * * *$ & - & & & & & \\
\hline Resilience & 5.62 & 0.66 & $.45^{* * *}$ & $.17^{* *}$ & - & & & & \\
\hline Satisfaction & 2.66 & 0.47 & .11 & $.23^{* * *}$ & $.16^{*}$ & - & & & \\
\hline Friction & 1.84 & 0.63 & -.06 & .12 & $-.15^{*}$ & $-.45 * * *$ & - & & \\
\hline Competitiveness & 2.25 & 0.53 & -.08 & $.16^{* *}$ & .00 & $-.1 * *$ & $.27 * * *$ & - & \\
\hline Difficulty & 1.77 & 0.66 & .03 & .03 & -.11 & -.06 & $.13 *$ & $.13^{*}$ & - \\
\hline Cohesiveness & 2.52 & 0.50 & .09 & .10 & $.13^{*}$ & $.48^{* * *}$ & $-.45^{* * *}$ & $-.12 *$ & -.12 \\
\hline
\end{tabular}

$* \mathrm{p}<.05, * * \mathrm{p}<.01, * * * \mathrm{p}<.001$

Table 2.

Hierarchical regression with resilience as the dependent variable and demographic variables, including academic performance, empathy, and altruism as the independent (predictor) variables.

\begin{tabular}{|c|c|c|c|c|c|c|c|}
\hline & & $\boldsymbol{\beta}$ & $\mathbf{T}$ & $\operatorname{Sig} \mathbf{T}$ & $\mathbf{R}^{2}$ & $\Delta \mathbf{R}^{2}$ & $\Delta \mathbf{F}$ \\
\hline \multirow[t]{7}{*}{ Demographics } & Gender &,- 07 & $-1,13$ &, 25 &, 05 &, 05 & 1,87 \\
\hline & Class &, 01 &, 15 &, 87 & & & \\
\hline & SES &, 08 & 1,23 &, 21 & & & \\
\hline & Siblings &,- 00 &,- 12 &, 89 & & & \\
\hline & Origin &, 10 & 1,5 &, 13 & & & \\
\hline & Language & 18 & 2,00 &, $04 *$ & & & \\
\hline & Mathematics & ,04 & ,44 & ,65 & & & \\
\hline Empathy & &, 14 & 2,05 &, $04 *$ & 07 &, 01 & 4,22 \\
\hline Resilience & &, 45 & 6,88 &, $00 * *$ &, 23 &, 16 & 47,38 \\
\hline
\end{tabular}

$* \mathrm{p}<.05, * * \mathrm{p}<.001$ 


\section{Altruism}

In order to examine the pattern of possible relations between altruism and the other variables in this study, namely empathy, resilience and classroom climate, one-way ANOVAs were carried out. The level of altruistic behavior exhibited by children differed significantly according to their level of a. empathy ( $\mathrm{F}$ $(35,196)=3.25, \mathrm{p}<.001)$; b. resilience $(\mathrm{F}(35,196)=2.24, \mathrm{p}$ $<.001)$; and c. competitiveness in the classroom $(\mathrm{F}(35,196)=$ $1.84, \mathrm{p}<.01)$. Higher altruism was accompanied by higher empathy and resilience and also by lower levels of competitiveness in the classroom.

Subsequently, a linear hierarchical regression (see Table 3, p. 382 for details) was performed to determine whether altruism could be predicted by participants' a. demographic characteristics, such as gender, class at school, socio-economic status, siblings and origin (dummy variables were created for these ordinal variables in order to be included in the regression equation); b. academic performance; c. empathy; d. resilience; and e. classroom climate. Altruism was found to be predicted by: a. gender (in particular, girls were more altruistic than boys); b. origin (students from European countries other than Greece were more altruistic than other students); c. academic performance in Mathematics (but, strangely not in Language); d. empathy; and e. resilience. Assessment of classroom climate did not appear to predict altruistic behavior.

\section{Discussion}

In this largely exploratory study, altruism in Greek pre-adolescent children appeared to be strongly related to demographic and personal characteristics, such as gender, academic performance and empathy, but also to the manifestation of resilience. With respect to gender, the above result was somewhat predictable, since altruism and consideration toward one's fellows in general are more congruent with the female role in our societies (Radke-Yarrow et al., 1983; Summers, 1987). Girls and women are largely expected - and, hence, raised in such a way as - to show more understanding and empathy towards others and also to act accordingly (Kakavoulis, 1999). Moreover, our finding is meaningful, insofar as it suggests that such societal expectations are initially internalized and subsequently find their way and shape children's manifest altruistic behavior (Radke-Yarrow \& Zahn-Waxler, 1986). In terms of the effects of origin on altruism, children in our sample who came from European countries scored higher on altruism than all others. Nevertheless, caution is warranted in generalizing this result, since only $3 \%$ of the sample came from other European countries. The presence of other children in the family did not seem to bear any importance for the manifestation of altruism in childhood, thus agreeing with empirical results which suggest that parenting style is the prime factor in helping children develop their altruistic tendencies (Eisenberg \& Morris, 2001). It is, however, worth examining sibling relations in more detail, since a number of theories, including social learning theory, ascertain the monumental effects of social imitation and symbolic interaction on modeling behaviors, values, beliefs and norms of significant others throughout development (Internet available: http://www.answers.com/topic/social-imitation-theory). Finally, academic performance, particularly in Mathematics, was found to be a strong predictor of childhood altruism. A process can be hypothesised, by which a number of intervening personal and social characteristics of the individual and his/her environment may facilitate the manifestation of prosocial behaviors. For instance, perhaps children who perform well at school also possess higher levels of self-esteem, which in turn may empower them to be positively predisposed toward engagement in altruistic behaviors. Such processes need to be studied in the future.

Links were found between altruism and empathy in our sample, thus supporting similar widely-accepted international findings (e.g. Eisenberg \& Mussen, 1997; Hoffman, 1981; Piliavin, 2009). Greek students were found to be similar to students elsewhere, in that altruism seemed to be facilitated by the empathic abilities of the individual. This finding needs to be taken a step further in order to explore any possible interactions between stress and adversity and the manifestation of a range of prosocial behaviors, as well as the influence of other personal and interpersonal characteristics, such as self-esteem, motivation and peer relations in childhood and adolescence within the context of positive psychology.

Table 3.

Hierarchical regression with altruism as the dependent variable and demographic variables, academic performance, empathy, resilience and classroom climate as the independent (predictor) variables.

\begin{tabular}{|c|c|c|c|c|c|c|c|}
\hline & & $\beta$ & $\mathbf{T}$ & Sig $\mathbf{T}$ & $\mathbf{R}^{2}$ & $\Delta \mathbf{R}^{2}$ & $\Delta \mathbf{F}$ \\
\hline \multirow[t]{5}{*}{ Demographics } & Gender & .21 & 3.32 & $.00^{* * *}$ & .07 & $.07 * *$ & 3.80 \\
\hline & Class & -.06 & -.97 & .33 & & & \\
\hline & SES & .09 & 1.48 & .14 & & & \\
\hline & Siblings & .04 & .65 & .51 & & & \\
\hline & Origin & .15 & 2.35 & $.01 * *$ & & & \\
\hline \multirow{2}{*}{ Academic performance } & Language & -.03 & -.34 & .730 & .11 & $.03 * *$ & 4.70 \\
\hline & Mathematics & .22 & 2.46 & $.01 * *$ & & & \\
\hline Empathy & & .31 & 4.89 & $.00 * * *$ & .20 & $.08 * * *$ & 23.96 \\
\hline \multirow[t]{3}{*}{ Resilience } & & .38 & 6.88 & $.00 * * *$ & .34 & $.14^{* * * *}$ & 47.38 \\
\hline & Satisfaction & -.03 & -.56 & .57 & .35 & .01 & .75 \\
\hline & Friction & .02 & .38 & .699 & & & \\
\hline \multirow[t]{3}{*}{ Classroom climate } & Competitiveness & -.07 & -1.29 & .19 & & & \\
\hline & Difficulty & .08 & 1.47 & .14 & & & \\
\hline & Cohesiveness & .02 & .32 & .74 & & & \\
\hline
\end{tabular}

$* \mathrm{p}<.05, * * \mathrm{p}<.01, * * * \mathrm{p}<.001$ 
To the best of our knowledge, altruism and resilience have hardly ever been examined together in a study, whether in Greece or abroad. The results of this study, which indicate that altruism can be reliably predicted by resilience are, therefore, important, as they open new horizons for the study of both concepts within the newly-established domain of positive psychology. The intricate ways in which children and adolescents manage to exhibit positive adaptation under adverse conditions, with the mediation and, possibly, moderation of prosocial behaviors, need to be further explored. In this way, our understanding of the extraordinary developmental and adaptational capabilities of human beings can be enriched and the human potential for positive growth fulfilled. The finding regarding the relations between altruism and resilience also offers support to the inclusion of emotional education programs and interventions for the promotion of resilience at the family level, but also at school and in the community, as suggested by (Leontopoulou, 2008). If altruism can aid the development of more resilient youth, then it can be included and practiced within the context of such programs. Many researchers make the case persuasively that positive aspects of human behavior can and need to be included as part of the school curriculum (Kohler \& Fowler, 1985; Triliva \& Chimienti, 2002).

Nevertheless, minimal evidence was found linking altruism and classroom climate - in particular, manifestation of altruistic behavior in children was found in classrooms with low competitiveness among students. While this finding points to the right direction, it is still surprising that no more connections were found between the two variables. It is possible that any relation between the two may have been masked by the significant correlations between altruism, empathy and resilience. Perhaps altruism is related to classroom climate via the mediation of empathy or resilience, or any number of other known variables, such as self-esteem or children's popularity; such a probability needs to be empirically tested. This finding can be alternatively interpreted as mirroring current practice in Greek schools, where emotional education is not taught, and therefore no connections are made by either students or teachers between positive aspects of human behavior such as altruism and empathy, and the classroom climate. This result can alternatively be construed as suggesting that altruism is largely thought to be a personal characteristic of the individual, and not necessarily linked to or affected by more social characteristics of one's environment. Perhaps such a link needs to be established, so that students, their parents and teachers themselves may become more aware of the important role that favourable external conditions in the classroom may play with regard to offering youths a supportive context, within which they are allowed and encouraged to demonstrate altruistic behavior.

This study also had a methodological focus, namely to establish the psychometric qualities of a new measure of altruism (ABQ) in children. Indeed, the high Cronbach's $\alpha$ found suggested that the scale has adequate internal consistency. Furthermore, the high correlations between altruism, and empathy and resilience indicated good concurrent validity for the new ABQ measure, when measured against the more established latter scales. This reassuring finding was not altogether surprising, since all three variables tap into concepts that measure positive aspects of the human experience, a finding that was supported by the fact that altruism, empathy and resilience all loaded on a single higher order factor, namely positivity. There was also some evidence that the ABQ has adequate construct validity, on the basis of the results of a hierarchical regression, which indicated that altruism contributed unique variance to the measurement of resilience, even after the effects of empathy were taken into account. Taken together, the above results offer preliminary support to the new ABQ measure having adequate psychometric qualities; nevertheless, more studies using this scale with youths of wide-ranging ages, alongside other similar measures, are needed to examine other aspects of the validity and reliability of this scale.

Limitations of the study included its cross-sectional nature, the use of a single method of data collection (i.e., self-report questionnaires) and the absence of other people's views with respect to students' altruistic behavior. Nevertheless, the encouraging results from this exploratory study, both in terms of the variables examined in relation to altruism and of the new scale which was developed and successfully tested here, lend themselves to further replication and extension with the use of more sophisticated data collection and analysis tools.

\section{References}

Block, J. (1993). Ego resilience through time. In Biennial Meeting of the Society of Research in Child Development. New Orleans, LA. Bollnow, O. (1970). Die pädagogische Atmosphäre. Heidelberg.

Bryant, B. (1982). An index of empathy for children and adolescents. Child Development, 53, 413-425.

Batson, C. D. (1991). The altruism question: Toward a social-psychological answer. Hillsdale, NJ: Lawrence Erlbaum Associates.

Comte, A. ([1851] 1975). System of positive polity (Vol. 1). London, UK: Longmans, Green, and Co.

Eisenberg, N. (1992). The caring child. Cambridge, MA: Harvard University Press.

Eisenberg, N., \& Morris, A. S. (2001). The origins and social significance of empathy-related responding, Social Justice, 14, 95-120.

Eisenberg, N., \& Mussen, P. H. (1997). The roots of prosocial behavior in children. Cambridge: Cambridge University Press.

Fraser, B. J., Anderson, G. J., \& Walberg, H. J. (1982). Assessment of learning environments: Manual for learning environment inventory LEI and my class inventory MCI. Perth, Australia: Western Australian Institute of Technology.

Friedman, E. (2007). HumanistNetworkNews.org, May 23, 2007. Internet available: http://americanhumanist.org/hnn/archives/index. php?id $=298 \&$ article $=1$.

Hay, D. F. (2009). Commentary. The roots and branches of human altruism. British Journal of Psychology, 100, 473-479.

Hoffman, M. L. (1981). Is altruism part of human nature? Journal of Personality and Social Psychology, 40, 121-137.

Hoffman, M. L. (2000). Empathy and moral development: Implications for caring and justice. Cambridge, U.K.: Cambridge University Press.

Internet available: http://www.answers.com/topic/social-imitation-theory Johnson, D. W., \& Johnson, R. T. (1983). Social interdependence and perceived academic and personal support in the classroom. Journal of Social Psychology, 120, 77-82.

Kakavoulis, A. K. (1997). Synaisthimatiki anaptyxi kai agogi $\left(2^{\text {nd }}\right.$ ed.). Athina: Ekdoseis Grigoris.

Kakavoulis, A. K. (1998a). Early childhood altruism: How parents see prosocial behavior in their young children. Early Child Development and Care, 140, 115-126.

Kakavoulis, A. K. (1999). Paidikos altruismos. Pos ta paidia ekdilonoun tin agapi toys: Theoritiki kai erevnitiki proseggisi. Athina: Aftoekdosi.

Kohler, F. W., \& Fowler, S. A. (1985). Training prosocial behaviors to 
young children: An analysis of reciprocity with untrained peers. Journal of Applied Behavior Analysis, 18, 187-200.

Leontopoulou, S. (2008). Psychiki anthektikotita kata tin efiveia: Psychokoinonikes paremvaseis stin oikogeneia, sto scholeio kai stin koinotita. In E. Kourkoutas and J.-P. Chartier (eds), Paidia kai efivoi me psychokoinonikes kai mathisiakes diataraches: Stratigikes paremvasis. Athina: Ekdoseis Topos.

Long, G. T., \& Lerner, M. J. (1974). Deserving the "personal contract" and altruistic behavior by children. Journal of Personality and Social Psychology, 29, 551-556.

Macaulay, J. R., \& Berkowitz, L. (Eds.) (1970). Altruism and helping behavior. New York: Academic Press.

Matsagouras, E. (2000). I Sxoliki Taxi Grigoris: Athina.

McGuire, K. D., \& Weisz, J. R. (1982). Social cognition and behavior correlates of preadolescense chumship. Child Development, 53, 1478-1484.

Mehrabian, A., \& Epstein, N. (1972). A measure of emotional empathy. Journal of Personality, 40, 525-543.

Midlarsky, E., \& Hannah, M. E. (1985). Competence, reticence, and helping by children and adolescents. Developmental Psychology, 21, 534-541.

Neill, J. T., \& Dias, K. L. (2001). Adventure Education and Resilience: The Double-Edged Sword. Journal of Adventure Education and Outdoor Learning, 12, 35-42.

Piliavin, J. A., Dovidio, J. F., Gaertner, S. L., \& Clark, R. D. (1981). Emergency intervention. New York: Academic Press.

Piliavin, J. A. (2009). Altruism and helping: the evolution of a field. Social Psychology Quarterly, 72, 209-225.

Radke-Yarrow, M., Zahn-Waxler, C., \& Chapman, M. (1983). Children's prosocial dispositions and behavior. In P. Mussen, \& E. M. Hetherington (Ed.), Manual of child psychology (Vol. 4: Socialization, personality, and social development, pp. 469-545). New York: Wiley.

Radke-Yarrow, M., \& Zahn-Waxler, C. (1986). Socialization in the family, childhood groups and society. In D. J. Olweus, M. Block, \& M. Radke-Yarrow (Eds.), Development of antisocial and prosocial behavior: Research, theories \& issues (Developmental Psychology Series). New York: Academic Press.

Rutter, M. (2000). School effects on pupil progress. Research findings and policy implications. In P. K. Smith \& A. D. Pellegrini (Eds.), Psychology of education: Major themes (Vol. 1, pp. 3-50). London: Falmer Press.

Seligman, M., Internet available: http://www.authentichappiness.sas. upenn.edu/Default.aspx\#

Sober, E., \& Wilson, D. S. (1998). Unto others: the evolution and psychology of unselfish behavior. Cambridge, MA: Harvard University Press.

Stalikas, A., \& Hamodraka, M. (2004). I ensynaisthisi stin psychotherapeia. Athina: Ellinika Grammata.

Stanton-Salazar, R. D., \& Spina, S. U. (2005). Adolescent peer networks as a context for social and emotional support. Youth \& Society, 36, 379-417.

Staub, E. (1971). Helping a person in distress: The influence of implicit and explicit rules of conduct on children and adults. Journal of Personality and Social Psychology, 17, 137-145.

Sutton, J., \& Keogh, E. (2000). Social competition in school: Relationships with bullying, Machiavellianism and personality. British Journal of Educational Psychology, 70, 443-456.

Triliva, S., \& Chimienti, G. (2002). Anakalipsi, autognosia, autokyriarchia, autoektimisi: Synaisthimatike kai koinonike epidexiotita. Ena egcheiridio technikon. Athina: Ekdoseis Pataki.

Wagnild, G. M., \& Young, H. M. (1993). Development and psychometric evaluation of the Resilience Scale. Journal of Nursing Measurement, 1, 165-178.

Warneken, F., \& Tomasello, M. (2009). The roots of human altruism. British Journal of Psychology, 100, 455-471.

Wispé, L. G. (1972). Positive forms of social behavior: An overview. Journal of Social Issues, 28, 1-19. 


\section{Appendix}

The Altruistic Behavior Questionnaire (ABQ)

Below are some sentences that describe ways with which children of your age sometimes behave toward others. We would like you to tell us how often you behave in the way that each sentence suggests. Put an ' $X$ ' in the box that shows how often you do what each sentence says. For example:

Do you apologise to a classmate when you have done something to upset him/her?

$\square$ Almost never $\quad \square$ Sometimes $\square$ Most of the time $\square$ Always

1. Do you offer something you own (e.g. pencil, rubber) to a classmate when he/she needs it?

2. Do you help a classmate when he/she has trouble with an exercise?

3. Do you try to make a classmate happy by playing with him/her or by saying a joke?

4. Do you cooperate with your classmates to achieve a good goal or target?

5. Do you and your classmates talk about how your vacations went?

6. Do you help two classmates when you see them having an argument?

7. Do you keep company to a classmate that is hurt during a game and cannot play with the rest of the team?

8. Do you invite a classmate who plays on his/her own to join you and your friends?

9. If you have candy or gum, do you offer any to your friends?

10. Do you protect your (younger) classmates when they find themselves in a difficult situation?

11. Do you spontaneously hug your classmates to show them how much you care about them?

12. When you play team games, do you choose to have a classmate in your team, even if he/she is not your friend?

13. Do you offer your seat to an adult at a school function?

14. Do you show a classmate how to play a sport he/she does not know how?

15. Do you reassure a classmate when he/she agonises over something that troubles him $/$ her?

16. Do you let another classmate to be the leader in the various games you play?

17. Do you share with your classmates a secret or a problem you have?

18. Do you help a new kid at school to feel more at home (e. g. keep him/her company, help him/her with schoolwork)?

19. Do you comfort a classmate who has received a poor mark in a course and is upset?

20. Do you keep quiet during class so that you don't bother your classmates? 